\title{
Review: Dietary fiber utilization and its effects on physiological functions and gut health of swine
}

\author{
R. Jha ${ }^{\dagger}$ and J. D. Berrocoso \\ Department of Human Nutrition, Food and Animal Sciences, College of Tropical Agriculture and Human Resources, University of Hawaii at Manoa, Honolulu, HI \\ 96822, USA
}

(Received 19 December 2014; Accepted 24 April 2015; First published online 22 May 2015)

\begin{abstract}
Although dietary fiber (DF) negatively affects energy and nutrient digestibility, there is growing interest for the inclusion of its fermentable fraction in pig diets due to their functional properties and potential health benefits beyond supplying energy to the animals. This paper reviews some of the relevant information available on the role of different types of DF on digestion of nutrients in different sections of the gut, the fermentation process and its influence on gut environment, especially production and utilization of metabolites, microbial community and gut health of swine. Focus has been given on DF from feed ingredients (grains and coproducts) commonly used in pig diets. Some information on the role DF in purified form in comparison with DF in whole matrix of feed ingredients is also presented. First, composition and fractions of DF in different feed ingredients are briefly reviewed. Then, roles of different fractions of DF on digestion characteristics and physiological functions in the gastrointestinal tract (GIT) are presented. Specific roles of different fractions of DF on fermentation characteristics and their effects on production and utilization of metabolites in the GIT have been discussed. In addition, roles of DF fermentation on metabolic activity and microbial community in the intestine and their effects on intestinal health are reviewed and discussed. Evidence presented in this review indicates that there is wide variation in the composition and content of DF among feed ingredients, thereby their physico-chemical properties in the GIT of swine. These variations, in turn, affect the digestion and fermentation characteristics in the GIT of swine. Digestibility of DF from different feed ingredients is more variable and lower than that of other nutrients like starch, sugars, fat and CP. Soluble fractions of DF are fermented faster, produce higher amounts of volatile fatty acid than insoluble fractions, and favors growth of beneficial microbiota. Thus, selective inclusion of DF in diets can be used as a nutritional strategy to optimize the intestinal health of pigs, despite its lower digestibility and consequential negative effect on digestibility of other nutrients.
\end{abstract}

Keywords: dietary fiber, digestion, fermentation, gut health, pig

\section{Implications}

This review provides relevant information on the utilization of dietary fiber (DF) by pigs and its effects on gut physiological functions, microbiota and health. This review delivers in-depth insight on both negative and positive effects of different fibers inclusion in swine diets. The DF lowers nutrient digestibility in swine. But, the fermentation of DF in the gut affects positively by modulating gut environment and potentially favoring 'beneficial bacteria', thereby improving gut health of pigs. These insights will help swine nutritionists and researchers in nutrition programing for better gut health of pigs by utilizing dietary fiber from different sources.

\footnotetext{
† E-mail: rjha@hawaii.edu
}

\section{Introduction}

During the last half century, there has been tremendous development in the field of pork production, resulting to more than 109 million tons of pork produced per year (FAO, 2013). This progress has been achieved by an intensification of the swine production systems, coupled with selective breeding programs and a better knowledge of pig nutrition. Feeding strategies based on antibiotics used as growth promoters aimed at improving the pig growth rate by improving its gut health status. However, there is a growing concern about the resistance of numerous bacteria to antibiotics used in human medicine, and is claimed to be due to the consumption of meat from animals grown with in-feed antibiotics, as meat from antibiotic-fed animals were found 
to have antibiotic-resistant bacteria (Gebreyes et al., 2006). Dietary fiber (DF) has been found to be an effective alternative to growth promoters (Verstegen and Williams, 2002), to improve gut health (Williams et al., 2001) by modulating gut microbiota, improve growth performance and reduce post-weaning diarrhea of the pigs (Mateos et al., 2006).

In commercial pig production, plant carbohydrates ( $\mathrm{CHO}$ ) represent the main fraction of a pig diet, accounting for more than $2 / 3^{\text {rd }}$ of the dry matter (DM; Bach Knudsen, 1997) and the single most abundant feed energy in diets for piglets, growing pigs and sows comprising $60.0 \%$ to $70.0 \%$ of total energy intake (Bach Knudsen et al., 2012). However, part of the CHO is not digested by the digestive enzymes of the small intestine and becomes available as a substrate for bacterial fermentation, mainly in the large intestine. This fraction, that is, DF, reduces nutrient and energy digestibility (Bach Knudsen, 2001; Noblet, 2007; Jha et al., 2010). Its physico-chemical properties (like solubility, viscosity and water-holding capacity (WHC)) also have a marked effect on nutrient digestibility along the gastrointestinal tract (Bach Knudsen and Hansen, 1991; Chabeauti et al., 1991; Molist et al., 2014).

Despite its negative impact on nutrient and energy digestibility (Bach Knudsen, 2001; Noblet, 2007; Jha et al., 2010), there is growing interest to include DF in pig diets, due to its possible effects on gut health, welfare and environment. Moreover, during the last decade, there has been dramatic shift in the landscape of the feed industry, in terms of price and availability of feed ingredients for animal feeds. There is increased availability of different alternative feed ingredients and coproducts from distillers and milling industries, which are rich sources of DF as well. However, it is important to know the implication of the use of these relatively new and potential DF sources in pig nutrition. Therefore, nutritionists are attempting to gain a more thorough understanding of inclusion of DF in pig diets.

To address the concerns and have a better understanding of DF and its role, this review has analyzed different aspects of DF in swine nutrition. More specifically, composition of DF in different feed ingredients (grains and coproducts) is first briefly reviewed. The digestibility and fermentability of the DF components in the gastrointestinal tract (GIT) of pigs and their effect on gut physiology, microbial environment and health are highlighted.

\section{DF}

\section{DF and its components}

The term 'dietary fiber' was first used by Hipsley in 1953 (De Vries et al., 1999) for 'the non-digestible constituents that make up the plant cell wall'. However, different definitions have been proposed and used over time. It is now accepted that an accurate definition of DF must include the physiological effects of fiber. Therefore, an important aspect of the definition is that DF consists of $\mathrm{CHO}$ that are indigestible by endogenous animal enzymes (AACC, 2001).

Broadly, DF includes cell wall compounds like cellulose, hemicelluloses, mixed linked $\beta$-glucan $(\beta \mathrm{G})$, pectins, gums and mucilages (Davidson and McDonald, 1998). Lignin, a complex phenolic compound, is also included in DF because it is a constituent of the plant cell walls that can greatly affect the digestibility of plant-derived foods (Theander et al., 1989). From a physiological point of view, non-starch polysaccharides (NSP), non-digestible oligosaccharides and resistant starch (RS) have to be included in the soluble DF fraction because they are not hydrolyzed by endogenous enzymes, and consequently, become available as substrates for microbial fermentation in the intestine (Cummings and Stephen, 2007).

\section{Sources of DF and interest for their use in swine diet}

The origin and composition of DF could be responsible for large variations in their utilization (Chabeauti et al., 1991). The physico-chemical properties of the DF sources may lead to changes in the gut environment, altering the growth of the gut microflora. The acceptability of the alternative feed ingredients in pig diets depends on several factors, like the DF content, the degree of microbial fermentation in the large intestine and the extent of absorption and utilization of the volatile fatty acid (VFA) produced (Molist et al., 2014). The fiber sources are fermented in the GIT producing VFA, which in turn positively affects gut health (Lindberg, 2014). Wellock et al. (2007) noted that gut health might benefit most from diets containing appropriate sources of predominantly soluble NSP rather than insoluble NSP. Soluble DF includes pectins, $\beta \mathrm{G}$, gum and hemicelluloses, while cellulose and lignin compromise the insoluble fraction (Davidson and McDonald, 1998). Thus, it is imperative to know the source and type of fiber being supplied in pig diets.

There is also increasing interest and incentive for the identification and characterization of alternative feed ingredients. These alternative feed ingredients include cereals and legume grains, distillery coproducts, coproducts from oil industry (like canola meal) and wheat flour milling (millrun and bran) and other fibrous feeds.

Cereal grains and their coproducts account for the major part of pig rations as main sources of energy. The DF of cereal grains are mainly composed of NSP (arabinoxylans, AX, $\beta \mathrm{G}$ and cellulose) and noncarbohydrate component lignin (Bach Knudsen, 2014). In addition, small amounts of pectin substances found in the stems and leaves of cereals (Choct, 1997). Several workers mentioned that the level of DF in the commonly available feed ingredients vary in relation to type and quality. As a reference to show the variation found in fiber components, the composition of some of the most common cereals and coproducts is presented in Table 1. Rye, wheat, corn and sorghum are all rich in $A X$, whereas barley and oats contain a high level of $\beta \mathrm{G}$. The $\mathrm{AX}$ from rye and wheat and $\beta \mathrm{G}$ from barley and oats are to a large extent soluble, whereas the solubility of $A X$ found in corn and sorghum is lower than the other cereals (Bach Knudsen et al., 2014).

Corn coproducts are typically rich in DF but variable in starch, amino acid and fat. The concentration and composition of DF of feed ingredients is important, because it may 
Fiber utilization and pig gut environment

Table 1 Types and levels of fiber components in some common cereal grains and coproducts ( $g / k g$ DM)

\begin{tabular}{|c|c|c|c|c|c|c|c|c|c|c|c|c|}
\hline & \multirow[b]{2}{*}{ Wheat $^{1}$} & \multicolumn{2}{|c|}{ Barley ${ }^{2,3,4}$} & \multicolumn{2}{|c|}{ Oats ${ }^{2,4}$} & \multirow[b]{2}{*}{ Corn $^{1}$} & \multirow[b]{2}{*}{ Sorghum ${ }^{1}$} & \multirow[b]{2}{*}{ Rye $^{2}$} & \multirow[b]{2}{*}{ Wheat bran ${ }^{2}$} & \multirow[b]{2}{*}{ Wheat middlings ${ }^{1}$} & \multirow[b]{2}{*}{$\mathrm{DDGS}^{1}$} & \multirow[b]{2}{*}{ Sugar beet pulp } \\
\hline & & Hulled & Hulless & Hulled & Hulless & & & & & & & \\
\hline Starch & 618 & 587 & 645 & 468 & 557 & 620 & 690 & 613 & 222 & 168 & 86 & 5 \\
\hline Cellulose & 13 & 39 & 10 & 82 & 14 & 17 & 15 & 15 & 72 & 67 & 58 & 203 \\
\hline \multicolumn{13}{|l|}{ NCP } \\
\hline Soluble & 19 & 56 & 50 & 40 & 54 & 25 & 4 & 42 & 29 & 12 & 34 & 290 \\
\hline Insoluble & 62 & 88 & 64 & 110 & 49 & 38 & 47 & 94 & 273 & 227 & 158 & 207 \\
\hline \multicolumn{13}{|l|}{ NSP } \\
\hline Arabinoxylans & 81 & 12 & 48 & 98 & 36 & 17 & 17 & 89 & 238 & 52 & 61 & 165 \\
\hline$\beta$-glucan & 8 & 43 & 42 & 28 & 41 & 6 & 1 & 20 & 24 & 21 & 63 & 8 \\
\hline Mannose & 2 & 2 & 4 & 3 & 3 & 2 & 1 & 3 & 5 & 19 & 9 & 8 \\
\hline Galactose & 3 & 2 & 3 & 7 & 4 & 8 & 3 & 3 & 9 & 13 & 14 & 38 \\
\hline Uronic acids & 4 & 2 & 2 & 10 & 5 & 8 & 4 & 2 & 15 & 16 & 16 & 199 \\
\hline Total NSP & 95 & 167 & 124 & 232 & 116 & 81 & 66 & 132 & 374 & 250 & 192 & 700 \\
\hline Lignin & 18 & 35 & 9 & 66 & 32 & 8 & 16 & 21 & 75 & 39 & 32 & 37 \\
\hline Dietary fiber & 112 & 202 & 133 & 298 & 148 & 89 & 83 & 153 & 449 & 289 & 322 & 737 \\
\hline
\end{tabular}

$\mathrm{DM}=$ dry matter; NCP = non-cellulosic polysaccharides; NSP = non-starch polysaccharides; DDGS $=$ distillers dried grains with solubles.

${ }^{1}$ According to Jaworski et al. (2015).

${ }^{2}$ According to Bach Knudsen (1997).

${ }^{3}$ According to Holtekjolen et al. (2006).

${ }^{4}$ According to tha et al. (2011a).

${ }^{5}$ According to Serena and Knudsen (2007).

reduce amino acid and energy digestibility (Noblet and Perez, 1993). The insoluble fraction of DF in corn and its coproducts is resistant to fermentation ( $40 \%$ is fermented in the entire GIT of the pigs), consisting of insoluble NSP such as cellulose, arabinoxylans and lignin (Bach Knudsen, 1997). Increasing the efficiency of starch and oil extraction from the corn grain, resulting in changes in chemical composition of corn coproducts, present a challenge to estimate their nutritional value (Gutierrez et al., 2014). In fact, Fairbairn et al. (1999) reported that NDF or ADF alone accounted for $68.0 \%$ and $85.0 \%$ of the total variation in digestible energy content of barley, respectively.

Wheat (Triticum aestivum) is primarily used in pig diets as source of energy. However, it contains significant amount of $D F$, including $A X, \beta G$ and cellulose. There are several wheat varieties, which vary widely in the amount and type of DF content. For example, in 12 wheat cultivars studied, ADF and NDF content ranged from $1.8 \%$ to $3.2 \%$ and $7.2 \%$ to $9.1 \%$, respectively (Jha et al., 2011c). Similarly, Kim et al. (2005) reported wide variation in the NSP and lignin contents of wheat while reviewing 426 samples dataset. The NSP content varied from $3.5 \%$ to $10.6 \% \mathrm{AX}, 0.3 \%$ to $1.2 \% \beta \mathrm{G}$ and $7.5 \%$ to $16.6 \%$ total NSP and the lignin content ranged from $0.9 \%$ to $1.1 \%$. This variation in amount and type of DF content of wheat can be attributed to different varieties (genetic makeup), growing locations and climate.

Barley (Hordeum vulgare L.) grains are relatively rich in DF such as $\beta G$, cellulose and $A X$. In particular, hulless barleys contain high levels of soluble $\beta \mathrm{G}$ (Izydorczyk et al., 2000), which are associated with health benefits for the gut (Brennan and Cleary, 2005). Even within hulless barleys, the variability in total DF, soluble and insoluble NSP is very wide
(Holtekjolen et al., 2006; Jha et al., 2011b). There is also wide variation in $\beta \mathrm{G}$ content within and between cereal types, ranging from $\sim 1.9 \%$ to $11.0 \%$ in barley, $1.7 \%$ to $7.0 \%$ in oats and $0.2 \%$ to $0.7 \%$ in wheat (Lee et al., 1997; Brennan and Cleary, 2005; Jha et al., 2011b). The rate of solubility of $\beta \mathrm{G}$ also varies, for example, Lambo et al. (2005) found that most of the $\beta \mathrm{G}$ in barley fiber were insoluble (about $85.0 \%$ ) whereas in oat, the opposite is observed, where about $68.0 \%$ of $\beta \mathrm{G}$ were found in soluble fiber fractions.

Oat (Avena sativa L.) contains both soluble and insoluble $\mathrm{DF}$, with high levels of $\beta \mathrm{G}, \mathrm{AX}$ and cellulose (Johansen et al., 1997; Jha et al., 2011b). Among the DF components of oat, $\beta G$ play an important role because of their functional properties in the GIT (Pieper et al., 2008; Jha et al., 2010).

Grain legumes are used in pig diets primarily as sources of protein and contain significant amounts of NSP as well. Cellulose and xylans are found in the hulls, whereas pectic polysaccharides are found in the cotyledons (Choct, 1997; Jha and Leterme, 2012).

The wheat flour milling industry generates a number of coproducts (wheat bran (WB), millrun, middlings, shorts, etc.), which are classified based on their DF content (Jha et al., 2012). These coproducts contain much higher DF than wheat as are enriched during processing of wheat to produce flour. In the six types of wheat flour milling coproducts studied, ADF and NDF content varied from $8.0 \%$ to $15.5 \%$ and $22.9 \%$ to $49.2 \%$, respectively (Jha et al., 2012).

Distillers dried grains with solubles (DDGS) is a coproduct from dry mill ethanol plants resulting from the fermentation of starch of cereal grains (corn, wheat, etc.) to produce fuel ethanol and carbon dioxide. Cereal grains are good source of 
starch, and as most of the starch is converted to ethanol during fermentation, which results in increased concentrations of the protein, oil and fiber that are two to three times higher than in the parent grain. Because of the depletion of most of the starch, the concentrations of $\mathrm{CHO}$ is lower than in the parent grain (Widmer et al., 2007) with most of the $\mathrm{CHO}$ present as fiber. The concentration of the different fiber fractions (NDF and ADF) and total DF is approximately three times greater in DDGS than in parent grains. However, the nutrient composition of DDGS varies depending on the ethanol plant where they are processed and the DDGS originating from different parent grains (Pedersen et al., 2014; Jha et al., 2015). The digestibility of fiber in DDGS is $<20.0 \%$ in the small intestine and $<50.0 \%$ over the entire GIT, and the DF, therefore, contributes relatively little to the energy value of these products. Moreover, low digestibility of DF in distillers coproducts results in increased quantities of manure being excreted from pigs fed these products, and the overall DM digestibility of diets containing distillers coproducts is lower than in corn-based diets (Pedersen et al., 2007). This lower digestibility of DDGS can be attributed to the complex fiber-starch-protein matrix (Jha et al., 2015), which limits the accessibility and action of endogenous enzymes for degradation. However, supplementation of exogenous multi-carbohydrase and protease enzymes may enhance the degradation of DDGS, thereby improving the nutrient release (Jha et al., 2015; Pedersen et al., 2015).

Canola meal is a coproduct derived after oil extraction processing, and can be used as ingredients in animal diets. $\mathrm{CHO}$ in canola seed may be categorized into soluble sugars and oligosaccharides, insoluble $\mathrm{CHO}$ and fiber. The concentration of soluble $\mathrm{CHO}$ in mature seeds is $\sim 10.0 \%$ of the oil-free weight, with sucrose ranging from $3.9 \%$ to $9.8 \%$, raffinose from $0.3 \%$ to $2.6 \%$, stachyose from $0.8 \%$ to $1.6 \%$, fructose from $0.1 \%$ to $0.5 \%$ and glucose from $0.1 \%$ to $0.4 \%$ (Barthet and Daun, 2011). The concentration of hemicellulose is $\sim 3.0 \%$, cellulose ranges from $4.0 \%$ to $5.0 \%$, and starch is $\sim 1.0 \%$ (Salunkhe et al., 1992). The concentration of crude fiber, NDF and ADF in canola meal ranges from $10.0 \%$ to $12.0 \%, 22.0 \%$ to $30.0 \%$ and $15.0 \%$ to $20.0 \%$, respectively. Canola meal has relatively high concentration of DF because hulls in canola seeds stay with the meal (Barthet and Daun, 2011). However, canola breeding programs have developed canola varieties with greater oil and protein content than traditional varieties. The new high-protein varieties of canola also contain less DF, and the resulting canola meal, therefore, has a reduced DF concentration compared with conventional canola.

\section{DF and digestion}

Effect of DF on digestion and physiological functions in gut Effect of DF on digestibility. Digestibility of DF is more variable $(40.0 \%$ to $60.0 \%)$ and lower than that of other nutrients like starch, sugars, fat and CP (above $80.0 \%$ in general). It is negatively affected by the amount and source of DF content in the diet (Noblet, 2007; Jha et al., 2010).
Consequently, the digestible energy content of diets is negatively and linearly affected by DF (Noblet, 2007). DF is better digested in adult sows than in growing pigs. The difference reaches $0.6 \mathrm{MJ} / \mathrm{kg} \mathrm{DM}$, on average (Noblet, 2007). This is ascribed to differences in the physiological stage of pigs as there is a higher rate of degradation of DF in the hindgut of sows, compared with growing pigs, due to longer retention time consecutive to their higher GIT volume, combined with a lower feed intake per live weight (Le Goff et al., 2002). However, it is not known if the DF in all cereal grains has similar effects on the digestibility of energy and nutrients in the diet. Just et al. (1983) found that every $1.0 \%$ of additional crude fiber in the diet decreases the gross energy digestibility by $1.3 \%$ and metabolizable energy by $0.9 \%$. The NSP, both in purified form and embedded within the matrix, also reduce CP digestion in pigs (Bedford et al., 1992; Jha et al., 2010). There is a linear decrease in apparent ileal digestibility of DM and CP with increased levels of purified NDF in the diet (Schulze et al., 1994) and lower organic matter, CP and starch digestibility in diets containing hulled barley, as compared with hulless barley-based diets in pigs. Also, Jha et al. (2010) reported that the lower organic matter and starch digestibility of the hulled barleys and oats was likely due to greater insoluble DF content, which negatively affects accessibility and the action of endogenous enzymes required for insoluble DF digestion in the upper gut and microbial fermentation in the lower gut.

On the other hand, the inclusion of the rice in the diet improves the digestibility of nutrients as compared with other cereal grains (Mateos et al., 2006; Cervantes-Pahn et al., 2014). These improvements in nutrient digestibility, especially gross energy, organic matter, starch and total $\mathrm{CHO}$ in rice diet, indicate that in young pigs, energy and nutrients from rice are better digested and absorbed than energy and nutrients from corn (Solá-Oriol et al., 2010).

The digestibility of nutrients in sorghum and wheat is relatively similar to that of corn, but in terms of grain structure and nutrient composition, sorghum is more similar to corn than to wheat (Taylor and Emmambux, 2010). But, CP digestibility of sorghum is less than corn. The reduced digestibility of CP in sorghum could be attributed to the binding of tannins to the protein in sorghum, which makes the protein resistant to proteolysis (Duodu et al., 2003). However, tannins content of the sorghum varies depending on the varieties and parts of the sorghum grain. Moreover, Wilfart et al. (2007b) reported decreasing apparent total tract digestibility of $\mathrm{DM}$, organic matter, CP and gross energy when added $0 \%, 20 \%$ and $40 \%$ WB $(16.5 \%, 20.9 \%$ and $27.0 \%$ total DF, respectively) to a wheat-barley-soybean meal diet. These authors suggested that digestion of the WB in the hindgut is affected by the time that the digesta is exposed to fermentation, and a rapid passage of digesta may reduce the efficacy of the digestion process. In fact, WB is one of the most effective fiber sources for increasing the rate of passage in the digestive tract.

Effect of DF on physiological functions. The presence of DF in the diet does not only affect digestibility but also other 
physiological functions in the gut. The latter are affected by the level and type of fiber (Schulze et al., 1995) and their physico-chemical properties, like WHC, solubility and viscosity (Leterme et al., 1996; Molist et al., 2014).

The presence of soluble DF in the diet increases digesta viscosity (Gallaher et al., 1999) and increased viscosity in the digesta can limit the interaction between nutrients and enzymes facilitating the formation of an unstirred water layer in the intestinal surface, thereby creating a physical barrier and consequently, reducing nutrient digestion and absorption. Moreover, insoluble DF sources such as WB are relatively resistant to microbial degradation (Jorgensen et al., 1996) and its inclusion in the diet produces an increase in fecal DM and bulkiness (Wilfart et al., 2007b). On the other hand, DF inclusion in the diet increases the endogenous nitrogen losses depending on DF level, type (Schulze et al., 1995) and physico-chemical properties such as WHC (Leterme et al., 1996). For example, soluble DF increases digesta viscosity and endogenous nitrogen losses (Mariscal-Landin et al., 1995). The high viscosity of the gut chyme stimulates the epithelial cell proliferation and may contribute to some loss of epithelial cells (Gee et al., 1996). In weanling pigs, Schiavon et al. (2004) reported that an increase in intestinal viscosity increased cell exfoliation in the apical part of the intestinal villus, causing atrophy and deeper crypt depth. Consequently, an increase in intestinal viscosity might reduce the digestion and absorption of nutrients in the diet (Molist et al., 2014). In this respect, Lizardo et al. (1997) reported decreasing apparent ileal digestibility in 25-day-old piglets fed a control diet or a same diet supplemented with $12.0 \%$ sugar beet pulp (SBP). In presence of $D F$, there is also an increase in the pancreatic secretions and the number of goblet cells (Schneeman et al., 1982). Moreover, there is increase in mucus secretion in the small intestine (Mariscal-Landin et al., 1995), which might be due to the mechanical effect of DF on the gut wall that affects the integrity of the mucus layer, resulting in superficial cell lesions (Schmidt-Willig et al., 1996). However, Leterme et al. (1998) did not observe any influence of insoluble NSP with high WHC on protein digestion and absorption, as opposed to soluble NSP with high WHC. In the study, the contrasted result of the effect of NSP on endogenous nitrogen losses was due to different sources of fibers used, which supports the findings that the source of DF with different physico-chemical properties behave differently and have different effects on nutrient digestibility and physiological properties in the gut.

It can be concluded that DF content negatively affects nutrient and energy digestibility, which varies according to the amount and source of DF and their physico-chemical properties. Moreover, different types of DF also exert their effect on different physiological functions in the gut.

\section{Degradability of DF in the upper and lower gut}

Degradability of DF in the upper gut

DF escapes enzymatic digestion in the small intestine and becomes available for fermentation by bacteria in the colon.
However, substantial degradation of DF may also occur in the small intestine (Jensen and Jorgensen, 1994; Jha et al., 2010; Jha and Leterme, 2012). Fiber-degrading bacteria are present in the stomach and in the proximal small intestine. They can partially disrupt the cell wall components of fiber, which leads to partial digestion (Varel and Yen, 1997). Bach Knudsen et al. (2008) summarized the ileal digestibility of NSP and their components from different studies. The results clearly indicate a wide variation in the digestion of NSP components, within and between different cereal sources. The wide variation in the fiber degradability can be ascribed to the physico-chemical properties of DF, the complexity of digestion/fermentation process, differences in experimental design, sample collection and analytical techniques. Gdala et al. (1997) reported lower digestibility of xylose, arabinose and uronic acids in the small intestine of piglets compared with glucose when fed diets based on cereals and soybean meal. This might be due to the high digestibility of mixed linked $\beta \mathrm{G}$, which is highly degradable in the upper gut, due to its soluble nature (Bach Knudsen and Hansen, 1991; Jha et al., 2010, 2011b). Also, Jha and Leterme (2012) suggested that the higher insoluble DF content of the different fiber sources such as WB or DDGS affects negatively to the accessibility and action of the endogenous enzymes in the upper gut and microbial fermentation in the lower gut, resulting in lower degradability of DF.

\section{Degradability of DF in the lower gut}

There is wide variation in the degradation of fiber in the large intestine, ranging from $48 \%$ to $95.0 \%$ (Bach Knudsen et al., 1993a; Jha et al., 2010; Jha and Leterme, 2012). Similarly, the total tract apparent digestibility of cellulose varies widely $(2.0 \%$ to $84.0 \%)$. Soluble pectin and hemicelluloses are digested to a greater extent than cellulose, while soluble $\beta \mathrm{G}$ from barley are almost completely digested by the end of the gut; the prececal digestibility has been found to range as high as $70.0 \%$ to $97.0 \%$ (Bach Knudsen et al., 1993a; Jha et al., 2010). On the other hand, insoluble branched-chain AX from wheat, rye and oat are less digestible in the pig gut (Bach Knudsen and Hansen, 1991; Glitsø et al., 1998). There are also noted effects of the DF source on variation in NSP digestibility. Chabeauti et al. (1991) found that the NSP digestibility in growing pigs varies from $16.3 \%$ for wheat straw, $43.5 \%$ for WB, and $69.5 \%$ for SBP to $79.1 \%$ for soybean hulls. The poor digestibility of WB is ascribed to their high lignin content that makes the NSP less fermentable compared with highly digestible pectin substances of SBP and soybean hulls (Karr-Lilienthal et al., 2005).

Gdala et al. (1997) analyzed the digestibility of different NSP residues in piglets and found that the rate and overall degradation of the polymers in the large intestine was largely influenced by the chemical nature of the DF, especially its solubility and degree of lignification. Similar results were obtained by Johansen et al. (1997) while studying the degradation of $\beta G$ and $A X$ from oat bran in the pig gut. However, the total loss of NSP from the anterior to terminal 
ileum was lower than reported by other workers in old pigs (Bach Knudsen and Hansen, 1991; Bach Knudsen et al., 1993a), possibly due to lower microbial activity in young piglets. Among the NSP components, soluble $\beta G, A X$ and pectins are rapidly degraded in the cecum and proximal colon while insoluble components of NSP like cellulose and insoluble $A X$ are degraded slowly and at the distal part of the colon (Bach Knudsen et al., 1993a; Glitsø et al., 1998; Canibe and Bach Knudsen, 2002). In this respect, Gidenne (2015) mentioned that the amounts of DF entering the cecum of rabbit is not a limiting factor for the fermentation processes, because the digesta retention time in the cecum of rabbit is very short as compared with pigs, and consequently, soluble fiber fractions such as pectins are degraded easily. Moreover, soluble and non-cellulosic mannose and galactose are highly digestible and fermentable compared with the insoluble cellulosic components of NSP (Serena and Knudsen, 2007).

\section{Fiber fermentation in the GIT}

\section{Fiber fermentation}

The susceptibility of DF to microbial fermentation varies depending on the accessibility of DF to the microbial population in the hindgut (Oakenfull, 2001). In monogastric animals, the large intestine is the most important site of fermentation (Williams et al., 2001). Fermentation of soluble DF is mainly at the proximal colon, whereas fermentation of insoluble DF is sustained until the distal colon (Choct, 1997). However, substantial fermentation of soluble DF has been observed in the pig's small intestine (Jensen and Jorgensen, 1994; Jha et al., 2010; Jha and Leterme, 2012). Fiber fermentation is an extremely complex process, affected by many factors in the GIT, including the host, its microflora and their interaction, which takes place between them (Williams et al., 2005).

Fiber fermentation and production of metabolites. Fermentation of DF is more variable than digestion of the macronutrients starch, fat and CP (generally above $80.0 \%$; Bach Knudsen et al., 2008). The variation in fermentability is mainly due to changes in physico-chemical properties of DF such as bulk, viscosity, solubility, WHC and fermentability. DF fermentation results in the production of VFA like acetate, propionate and butyrate, along with some gases like hydrogen, carbon dioxide and methane (Macfarlane and Macfarlane, 1993; Williams et al., 2001). Acetate is the most abundant VFA, comprising about $60.0 \%$ of the total VFA produced in the hindgut, whereas propionate and butyrate are produced in smaller quantities (Lunn and Buttriss, 2007). However, the extent of fermentation and the profile in VFA depend on the substrate (Salvador et al., 1993; Jha et al., 2012) while the rate of fermentation of DF in the pig's intestines depends on its composition and physico-chemical properties, degree of lignification and particle size (Le Goff et al., 2003) and transit time in the digestive tract (Wilfart et al., 2007a). Soluble DF has, in general, a higher WHC than insoluble DF that give raise to a larger surface area and thereby large areas for bacterial enzyme attack. Thus, these characteristics are directly dependent on the botanical origin and (or) processing of the DF source (Johansen et al., 1997).

In addition to VFA, other metabolites such as lactate, ethanol and succinate are also produced from bacterial fermentation of DF (Drochner et al., 2004). The majority of these metabolites (possibly except ethanol) are further converted into VFA by cross-feeding mechanisms (Macfarlane and Gibson, 1995).

Fate of fermentation metabolites in the pig large intestine. The main site of VFA absorption in pigs is the large intestine (Imoto and Namioka, 1978) where the majority (about $90.0 \%$ ) of the VFA are absorbed and metabolized (Jorgensen et al., 1997).

The VFA are absorbed in the gut through passive diffusion. The exact mechanism for absorption is still unclear. However, several mechanisms have been proposed, stating their dependence on luminal $\mathrm{pH}, \mathrm{CO}_{2}$, as well as the fluxes of water, protons and inorganic ions (Bugaut, 1987). The fermentation metabolites are taken up by the cells in the intestines and used for bacterial growth (Bach Knudsen, 2001). Although VFA are primarily taken up and metabolized by colonocytes, these are also used as a source of energy by other tissues (Wong et al., 2006). The absorbed VFA are basically metabolized in three major sites: in the ceco-colonic epithelial cells that use butyrate for their energy production pathway; liver cells that metabolize residual butyrate and propionate for gluconeogenesis, as well as $50.0 \%$ to $70.0 \%$ of acetate; and muscle cells, mainly from skeletal and cardiac muscles that oxidize the residual acetate (Roberfroid, 2007). The energy produced from VFA may contribute up to $15.0 \%$ of the maintenance energy requirements of growing pigs (Dierick et al., 1989) and even up to $30.0 \%$ in gestating sows (Varel and Yen, 1997).

Absorption of VFA also facilitates absorption of other nutrients from the diet. Water and sodium are absorbed along with VFA (Yen, 2001). Plant lignans, diphenolic compounds similar to endogenous steroid hormones, are also co-transported by VFA (Bach Knudsen et al., 2006).

\section{Effect of source of fiber on metabolite production}

Among the non-digestible oligosaccharides, fructooligosaccharides (FOS) are the most extensively studied. The FOS contains 2-70 fructose residues and Bifidobacteria can digest them as they produce the enzyme fructofuranosidase (Gibson et al., 2004). FOS are fermented by bacteria, yielding energy for bacterial growth. Houdijk et al. (2002) evaluated the effect of FOS and transgalactooligosaccharides (TOS) in comparison with non-fiber control diets in weaned pigs and found that both FOS and TOS increased VFA production in the gut. However, there were differences in the concentration of VFA in different sections of the gut between FOS and TOS fed pigs, which supports the view that FOS and TOS have different fermentation characteristics in the GIT of the pigs.

Among the $\mathrm{DF}$ fractions, $\beta \mathrm{G}$ is gaining more attention as it is a source of easily fermentable energy for intestinal 
microbiota. It yields higher levels of VFA (Brennan and Cleary, 2005) due to a relatively high concentration, soluble state and high molecular weight and results in several beneficial physiologic effects to the host (Dongowski et al., 2002). Oat bran, a rich source of soluble DF in the form of $\beta G$, produces almost twice as much VFA per gram DF as WB in the pig intestines (Bach Knudsen and Hansen, 1991; Bach Knudsen et al., 1993a). However, AX and not $\beta \mathrm{G}$ in the cell walls of oat bran are responsible for the enhanced butyric acid production of oat bran (Bach Knudsen et al., 1993b). Bach Knudsen and Canibe (2000) found higher concentrations and flows of lactic acid in the ileum of cannulated pigs after feeding a diet supplemented with soluble DF from oat bran, which supports the view that $\beta \mathrm{G}$ stimulates the production of lactic acid in the small intestine, which is found to promote the development of Lactobacilli, a family of healthpromoting bacteria.

There are noted effects of DF on VFA production and profile, depending on type and source of DF. For example, Freire et al. (2000) compared the effects of inclusion in the diet of $20.0 \%$ of WB, SBP, soybean hulls or alfalfa meal on concentration of the total VFA in the cecum and reported that the inclusion of soybean hulls in the weaning diet increased the concentration of total VFA by $11.2 \%, 30.5 \%$ and $27.2 \%$ as compared with WB, SBP and alfalfa diets, respectively. The values suggests that soybean hulls is highly degraded in the cecum, and is in agreement with the high digestibility values of the NDF and ADF fractions reported in this research. Also, the lower values of VFA measured in the SBP diet might also be associated with a higher absorption rate of its metabolites in the cecum. Carneiro et al. (2008) compared the effect of two fiber sources, WB and maize cobs in weaned pigs and found no difference in the amounts of VFA in the small intestine. However, there was higher acetic acid and lower butyric acid production in the cecum when WB was replaced with maize cobs. Findings of these studies clearly indicate that not only the amount and type of substrate, but also the source of fiber fraction is important to determine the amount and type of VFA production.

\section{Effect of fiber fermentation on gut microbiota}

The influence of diet on microbial communities in the pig intestines has been of interest for long time. However, the interaction of diet and microbiota in the intestines of the pig are still not well understood.

The GIT microbiota of pig is composed primarily of bacteria. The microbial population increases from $10^{3}$ to $10^{5} / \mathrm{g}$ of digesta in the stomach to $10^{9}$ to $10^{10}$ in the distal small intestine, and further to $10^{10}$ to $10^{11}$ in the large intestine of pigs, belonging to more than 50 genera and over 500 species of bacteria (Jensen and Jorgensen, 1994; Gaskins, 2001). The majority (about $90.0 \%$ ) of the cultivable bacteria are Gram-positive, strict anaerobes belonging to the Streptococcus, Lactobacillus, Eubacterium, Clostridium and Peptostreptococcus genus while the remaining $10.0 \%$ of total flora belongs to Gram-negative of Bacteroides and Prevotella groups (Gaskins, 2001). Each bacterial species occupies a particular niche with numerous interrelationships between them (Flint et al., 2008).

Effect on microbial composition. The population and activity of bacteria in the gut is influenced by several factors, the main one being diet (Bach Knudsen et al., 2012). More specifically, the structure and composition (Konstantinov et al., 2004; Bindelle et al., 2010), solubility (Hogberg and Lindberg, 2004) and amount and type of substrate available (Macfarlane and Macfarlane, 1993) affects the gut microbial ecology. Among the different constituents of diets, DF is found to affect the gut environment (Awati et al., 2005; Jha et al., 2010; Jha and Leterme, 2012). The source of DF affects the digestion site and gut environment, thereby affecting the conditions for the proliferation of microbiota in the gut (Hogberg and Lindberg, 2004). Moreover, DF serves as an energy source for microbes and supports their proliferation. Gidenne (2015) reported that the energy provided by the cecal VFA could reach up to $50 \%$ of the maintenance energy in growing rabbit. In pigs, Bach Knudsen et al. (1991) reported 5.5 times (as measured by ATP concentration) increased microbial activity in the GIT of pigs when fed with a high-fiber diet. In addition, there was increased (five to nine times) carbon dioxide and methane production, suggesting increased microbial fermentation that takes place in the GIT of pigs fed a high-fiber diet. Similar increased microbial activity was observed in the intestines of pigs fed pea fiber and pectin, as indicated by higher bacterial counts, ATP concentration, adenylate energy charge and low $\mathrm{pH}$ (Jensen and Jorgensen, 1994). However, Varel et al. (1982) noted that there was initially a decrease in the bacterial population of the pig intestines when the animals were fed with high-fiber diet (50.0\% alfalfa meal) in lean genotype pigs. The microbial population, however, increased after continuous fiber-feeding for 17 weeks. It suggests that there is some kind of adaptation of the microbiota in the pig intestines when fed with high DF diets.

DF affects fermentation in the GIT by stimulating the growth or metabolism of special bacterial species (Williams et al., 2001). These increased numbers of cellulolytic bacteria enhance the hindgut fermentation and production of VFA, which decreases the $\mathrm{pH}$ of the gut content. A decrease in $\mathrm{pH}$ promotes growth of beneficial bacteria (e.g. Bifidobacteria spp., Lactobacilli spp.), at the expense of pathogenic ones like Clostridium or Salmonella, which contribute to enhance the health of host species (Bouhnik et al., 2004). This phenomenon is termed as 'prebiotic effect' (Gibson and Roberfroid, 1995).

The potential 'prebiotic effect' of DF has been studied in several monogastric species, including swine. The results are quite variable from one study to another in terms of their effect on microbial population, diversity and gut health, which can be ascribed to the type of substrate available for fermentation and the gut environment of the host. At the increased level of DF in the large intestine, there is an increase in activity of the entire microbial community. However, some types of DF may have selective effects and 
stimulate particular niches of microorganisms (Louis et al., 2007).

Estrada et al. (2001) found increased numbers of Bifidobacteria spp. and decreased numbers of total anaerobes and Clostridia in feces of pigs fed with diets containing $0.5 \%$ FOS in conjunction with Bifidobacterium longum. Drew et al. (2002) compared the effect of $\mathrm{CHO}$ sources (corn, wheat and barley) in weaned pigs and found that the bacterial population was significantly related with ADF and NDF contents of the diets. There were increased Lactobacilli spp. and decreased Enterobacteria spp. populations in barleyfed pigs, as compared with corn-fed pigs. Moreover, barleybased diets increased Lactobacilli spp. and Bifidobacterium spp. in the cecum, compared with corn-based diets. One possible explanation might be the higher amount of $\beta \mathrm{G}$ in barley-based diets, compared with corn-based diets, which is found to enhance the growth of beneficial bacteria at the cost of harmful bacteria. In fact, Pieper et al. (2008) reported that dietary $\beta \mathrm{G}$ in barley-based diets increases colonic lactobacilli spp. and bifidobacteria spp. promoting butyrateproducing bacteria. Interestingly, wheat-based diets had higher numbers of Bifidobacterium spp. and lower numbers of total aerobes and Clostridium spp., compared with barleybased diets. Similarly, Nielson et al. (2014) reported that pigs fed with diet rich in AX resulted in higher levels of Bifidobacterium spp. and Lactobacillus spp. in the feces. These can be ascribed to the complexity of the various bacterial species and fermentable substrates present, especially the monomers of the fiber, which are selective for certain microbes. Konstantinov et al. (2004) found Ruminococcus-like species in the feces of pigs fed diets containing fibers (SBP and FOS), but not in pigs fed a control diet, suggesting that these bacteria may play a role in the utilization of DF. Moreover, there was a specific response of a novel and abundant Lactobacillus amylovorus-like phylotype to dietary oligosaccharides in the gut of weaning pigs (Konstantinov et al., 2004). Similarly, Owusu-Asiedu et al. (2006) reported increased Bifidobacteria spp. and Enterobacteria spp. populations in the ileal digesta of growing pigs fed diets supplemented with guar gum or cellulose to a standard diet.

The effects of NSP compounds such as $\beta$ G and AX have mainly been studied in isolated form, whereas in swine diets, these compounds are present as part of the grain matrix. The fermentation rate of these $\mathrm{CHO}$ in the intestinal tract will thus depend on their composition, form and physical properties (Le Goff et al., 2003). As a consequence, cereal NSP in isolated form or within a matrix may act differently in the GIT. In this respect, Pieper et al. (2008) conducted an experiment with weaned pigs and found that hulless barley varieties with high soluble NSP content favored xylan- and $\beta \mathrm{G}$-degrading bacteria, whereas $\beta \mathrm{G}$-supplemented hulled barleys favored Lactobacilli spp. Moreover, there was a decrease in the number of Lactobacilli spp. in the ileum of pigs fed hulless/high $\beta \mathrm{G}$ barley-based diets. This suggests that both type and form of $\beta \mathrm{G}$ affect the bacterial population in the pig intestines. Processed fibers are also found to exert a positive response on health-promoting characteristics. As an example, oat fiber and $\beta \mathrm{G}$ isolates, fermented ropy oat-based products containing both native and microbial $\beta \mathrm{G}$, stimulated Bifidobacteria spp. in the GIT apart from other health benefits like reduced blood cholesterol level to host (Martensson et al., 2005). Like the NSP, RS is also found to affect the bacterial population in the pig intestines. Brown et al. (1997) found higher Bifidobacteria spp. counts in feces of pigs fed with a high amylose cornstarch diet, than in feces of pigs fed with a low amylose cornstarch. Part of the high amylose corn-starch becomes RS, which is fermented in the large intestine and exerts prebiotic effects.

Effect on gut health. The maintenance of gut health is complex phenomenon and relies on a delicate balance between the diet, the commensal microflora and the mucosa, including the digestive epithelium and the mucus overlying the epithelium (Montagne et al., 2003). DF plays an important role in the function of the pig GIT. It is evidenced by several studies reporting the positive role of DF in controlling bacterial infections, particularly reducing post-weaning diarrhea (Williams et al., 2001; Mateos et al., 2006; Molist et al., 2014), which is a major problem for the pig industry in many parts of the world. In this respect, Lizardo et al. (1997) reported improved digestive function in 39-day-old pigs when $12.0 \%$ SBP was included in the diet. Probably, soluble fiber sources such as SBP, are easily fermentable by the microflora in the large intestine, which could help to create a stable environment within the GIT reducing the incidence of post-weaning diarrhea. Thomsen et al. (2007) observed that the inclusion of DF, like fructan-rich chicory roots and sweet lupins completely protected against the development of swine dysentery. Similarly, the inclusion of DF in piglet diets enhanced intestinal populations of Lactobacilli spp. and reduced the incidence and severity of diarrhea (Edwards, 1996). These studies support the view that diets supplemented with fiber can protect pigs against swine dysentery. However, there is continuous debate on whether fiber exerts beneficial or detrimental effects on the development of postweaning enteric dysentery. Pluske et al. (2003) noted increased incidence of clinical swine dysentery in growing pigs and diarrhea in weanling pigs fed with diets high in fermentable NSP and RS. Similar negative effect on gut health was also noticed with supplementation of isolated soluble fiber. Nursery pig diets supplemented with $0.025 \%$ $\beta G$ increased growth performance but also increased the susceptibility to Streptococcus suis infection (Dritz et al., 1995). These authors suggest that a complex interaction exists between growth performance and disease susceptibility in pigs fed $\beta G$.

There is some information available on fractions of DF of other grains like peas, chickpeas, faba beans and lupins and their effect on microbial population and gut health. QueirozMonici et al. (2005), while working with rats, found that peas and chickpeas have a bifidogenic effect due to the DF and RS present in these legumes. RS is considered a good source of butyrate production, which is utilized by the colonic cells as 
fuel, thus strengthening the first line of defense in the gut (Topping and Clifton, 2001). Thus, RS sources with the potential to stimulate butyrate production have a potential to improve gut health.

It can be summarized that the presence of fiber in the gut significantly affects the gut microbial environment, creates more favorable lumen conditions for gut health by stimulating the growth of 'beneficial bacteria' at the cost of 'harmful bacteria', with the possibility of some negative impact on gut health, which depends on the type of fiber substrate available for fermentation. However, there is no straightforward answer of the benefits of DF on gut health and direct evidence for enhanced resistance to unfavorable conditions is still lacking.

\section{Conclusion}

There is wide variation found in the composition of DF in different feeds and feed ingredients, which has a major impact on their physico-chemical properties and digestion and fermentation characteristics in the GIT. In general, DF affects nutrients and energy digestibility in pigs negatively but with differences between the different types: (1) soluble DF fractions are fermented faster than insoluble fractions, produce higher amounts of VFAs and lower ammonia concentrations; (2) some DF constituents, for example RS, may stimulate butyrate production to a higher degree than others thereby contributing to an improved gut health; and (3) some DF constituents may exert 'prebiotic effects', enhancing 'beneficial bacteria' at the cost of 'harmful bacteria' in the pig gut. Therefore, strategic selection of DF in diets can be used as a nutritional strategy to modulate the intestinal health of swine.

\section{Acknowledgement}

This work was partially supported by USDA National Institute for Food and Agriculture, Hatch Project HAW02030-H administered by the College of Tropical Agriculture and Human Resources, University of Hawaii at Manoa.

\section{References}

AACC 2001. The definition of dietary fiber. AACC report. American Association of Cereal Chemists 46, 112-126.

Awati A, Konstantinov SR, Williams BA, Akkermans ADL, Bosch MW, Smidt H and Verstegen MWA 2005. Effect of substrate adaptation on the microbial fermentation and microbial composition of faecal microbiota of weaning piglets studied in vitro. Journal of the Science of Food and Agriculture 85, 1765-1772. Bach Knudsen KE 1997. Carbohydrate and lignin contents of plant materials used in animal feeding. Animal Feed Science and Technology 67, 319-338.

Bach Knudsen KE 2001. The nutritional significance of 'dietary fibre' analysis. Animal Feed Science and Technology 90, 3-20.

Bach Knudsen KE 2014. Fiber and nonstarch polysaccharide content and variation in common crops used in broiler diets. Poultry Science 93, 2380-2393.

Bach Knudsen KE and Hansen I 1991. Gastrointestinal implications in pigs of wheat and oat fractions 1. Digestibility and bulking properties of polysaccharides and other major constituents. British Journal of Nutrition 65, 217-232.
Bach Knudsen KE and Canibe N 2000. Breakdown of plant carbohydrates in the digestive tract of pigs fed on wheat- or oat-based rolls. Journal of the Science of Food and Agriculture 80, 1253-1261.

Bach Knudsen KE, Jensen BB and Hansen I 1993a. Digestion of polysaccharides and other major components in the small and large intestine of pigs fed on diets consisting of oat fractions rich in $\beta$-D-glucan. British Journal of Nutrition 70, 537-556.

Bach Knudsen KE, Jensen BB and Hansen I 1993b. Oat bran but not a betaglucan-enriched oat fraction enhances butyrate production in the large intestine of pigs. The Journal of Nutrition 123, 1235-1247.

Bach Knudsen KE, Laerke HN and Jorgensen $\mathrm{H}$ 2008. The role of fibre in nutrient utilization and animal health. In Proceedings of the 29th Western Nutrition Conference, September 23-24, Edmonton, AB, Canada, pp. 93-107.

Bach Knudsen KE, Hedemann MS and Laerke HN 2012. The role of carbohydrates in intestinal health of pigs. Animal Feed Science and Technology 173, 41-53.

Bach Knudsen KE, Jensen BB, Andersen JO and Hansen I 1991. Gastrointestinal implications in pigs of wheat and oat fractions 2. Microbial activity in the gastrointestinal tract. British Journal of Nutrition 65, 233-248.

Bach Knudsen KE, Serena A, Jørgensen H, Peñalvo JL and Adlercreutz H 2006. Rye and other natural cereal fiber enhance the production and plasma concentration of enterolactone and butyrate. In Dietary fiber components and functions (ed. H Salovaara, F Gates and M Tenkanen), pp. 219-235. Wageningen Academic Publishers, Wageningen, The Netherlands.

Barthet VJ and Daun JK 2011. Seed morphology, composition, and quality. In Canola: chemistry, production, processing, and utilization (ed. JK Daun, NAM Eskin and D Dickling), pp. 119-162. AOCS Press, Urbana, IL, USA.

Bedford MR, Patience JF, Classen HL and Inborr J 1992. The effect of dietary enzyme supplementation of rye- and barley-based diets on digestion and subsequent performance in weanling pigs. Canadian Journal of Animal Science 72, 97-105.

Bindelle J, Pieper R, Leterme P, Rossnagel B and Van Kessel AG 2010. Changes in intestinal microbial ecophysiology as related to the carbohydrate composition of barleys and oats cultivars in an in vitro model of the pig gastrointestinal tract. Livestock Science 133, 151-153.

Bouhnik Y, Raskine L, Simoneau G, Vicaut E, Neut C, Flourié B, Brouns $F$ and Bornet FR 2004. Capacity of nondigestible carbohydrates to stimulate bifidobacteria in healthy humans. American Journal of Clinical Nutrition 80, 1658-1664. Brennan CS and Cleary LJ 2005. The potential use of cereal (1/3,1/4)- $\beta$-D-glucans as functional food ingredients. Journal of Cereal Science $42,1-13$.

Brown I, Warhurst M, Arcot J, Playne M, Illman RJ and Topping DL 1997. Fecal numbers of bifidobacteria are higher in pigs fed Bifidobacterium longum with a high amylose cornstarch than with a low amylose cornstarch. The Journal of Nutrition 127, 1822-1827.

Bugaut M 1987. Occurrence, absorption and metabolism of short chain fatty acids in the digestive tract of mammals. Comparative Biochemistry and Physiology B 86, 439-472.

Canibe $\mathrm{N}$ and Bach Knudsen KE 2002. Degradation and physicochemical changes of barley and pea fibre along the gastrointestinal tract of pigs. Journal of the Science of Food and Agriculture 82, 27-39.

Carneiro MSC, Lordelo MM, Cunha LF and Freire JPB 2008. Effects of dietary fibre source and enzyme supplementation on faecal apparent digestibility, short chain fatty acid production and activity of bacterial enzymes in the gut of piglets. Animal Feed Science and Technology 146, 124-136.

Cervantes-Pahm SK, Yanhong L and Stein HH 2014. Comparative digestibility of energy and nutrients and fermentability of dietary fiber in eight cereal grains fed to pigs. Journal Science Food Agriculture 94, 841-849.

Chabeauti E, Noblet J and Carre B 1991. Digestion of plant cell walls from four different sources in growing pigs. Animal Feed Science and Technology 32, 207-213.

Choct M 1997. Feed non-starch polysaccharides: chemical structures and nutritional significance. Feed Milling International 6, 13-26.

Cummings JH and Stephen AM 2007. Carbohydrate terminology and classification. European Journal of Clinical Nutrition 61, 5-18.

Davidson $\mathrm{MH}$ and McDonald A 1998. Fiber: forms and functions. Nutrition Research 18, 617-624.

DeVries JW, Prosky L, Li B and Cho S 1999. A historical perspective on defining dietary fiber. Cereal Foods World 44, 367-369.

Dierick NA, Vervaeke IJ, Demeyer DI and Decuypere JA 1989. Approach to the energetic importance of fibre digestion in pigs. I. Importance of fermentation in the overall energy supply. Animal Feed Science and Technology 23, 141-167. 
Dongowski G, Huth M, Gebhardt E and Flamme W 2002. Dietary fiber-rich barley products beneficially affect the intestinal tract of rats. The Journal of Nutrition 132, 3704-3714.

Drew MD, Van Kessel AG, Estrada AE, Ekpe ED and Zijlstra RT 2002. Effect of dietary cereal on intestinal bacterial populations in weaned pigs. Canadian Journal of Animal Science 82, 607-609.

Dritz SS, Shi J, Kielian TL, Goodband RD, Nelssen JL, Tokach MD Chengappa MM, Smith JE and Blecha F 1995. Influence of dietary beta-glucan on growth performance, nonspecific immunity, and resistance to Streptococcus suis infection in weanling pigs. Journal of Animal Science 73, 3341-3350.

Drochner W, Kerler A and Zacharias B 2004. Pectin in pig nutrition, a comparative review. Journal of Animal Physiology and Animal Nutrition 88, 367-380.

Duodu KG, Taylor JRN, Belton PS and Hamaker BR 2003. Mini review: factors affecting sorghum protein digestibility. Journal Cereal Science 38, 117-131.

Edwards SA 1996. A new look on the role of fibre in the diet of pigs. In Proceedings of the $6^{\text {th }}$ European Society of Veterinary Internal Medicine, September 12-14, Veldhoven, The Netherlands, pp. 90-91.

Estrada A, Drew MD and Van Kessel AG 2001. Effect of dietary supplementation of fructooligosacchadies and Bifidobacterium longum to early weaned pigs on performance and fecal bacterial populations. Canadian Journal of Animal Science 81, 141-148.

Fairbairn SL, Patience JF, Classen HL and Zijlstra RT 1999. The energy content of barley fed to growing pigs: characterizing the nature of its variability and developing prediction equations for its estimation. Journal of Animal Science 77, 1502-1512.

FAO Statistical Yearbook 2013. World food and agriculture. Food and Agriculture Organization of the United Nations, pp. 172. Rome, Italy.

Flint HJ, Bayer EA, Rincon MT, Lamed R and White BA 2008. Polysaccharide utilization by gut bacteria: potential for new insights from genomic analysis. Nature Reviews Microbiology 6, 121-131.

Freire JPB, Guerreiro AJG, Cunha LF and Aumaitre A 2000. Effect of dietary fibre source on total tract digestibility, caecum volatile fatty acids and digestive transit time in the weaned piglet. Animal Feed Science and Technology 87, 71-83.

Gallaher DD, Wood KJ, Gallaher CM, Marquart LF and Engstrom AM 1999. Intestinal contents supernatant viscosity of rats fed oat-based muffins and cereal products. Cereal Chemical 76, 21-24.

Gaskins HR 2001. Intestinal bacteria and their influence on swine growth. In Swine nutrition, 2nd edition (ed. AJ Lewis and LL Southern), pp. 585-608. CRC Press, Boca Raton, FL, USA

Gdala J, Johansen HN, Bach Knudsen KE, Knap IH, Wagner P and Jørgensen OB 1997. The digestibility of carbohydrates, protein and fat in the small and large intestine of piglets fed non-supplemented and enzyme supplemented diets. Animal Feed Science and Technology 65, 15-33.

Gebreyes WA, Thakur S and Morrow WEM 2006. Comparison of prevalence, antimicrobial resistance, and occurrence of multidrug-resistant Salmonella in antimicrobial-free and conventional pig production. Journal of Food Protection 69, 743-748.

Gee JM, Lee-Finglas W, Wortley GW and Johnson IT 1996. Fermentable carbohydrates elevate plasma enteroglucagon but high viscosity is also necessary to stimulate small bowel mucosal cell proliferation in rats. The Journal of Nutrition 126, 373-379.

Gibson GR and Roberfroid MB 1995. Dietary modulation of the human colonic microbiota: introducing the concept of prebiotics. The Journal of Nutrition 125, 1401-1412.

Gibson GR, Probert HM, Loo JV, Rastall RA and Roberfroid MB 2004. Dietary modulation of the human colonic microbiota: updating the concept of prebiotics. Nutrition Research Reviews 17, 259-275.

Gidenne T 2015. Dietary fibres in the nutrition of the growing rabbit and recommendations to preserve digestive health: a review. Animal 9, 227-242.

Glitsø LV, Brunsgaard G, Højsgaard S, Sandström B and Bach Knudsen KE 1998 Intestinal degradation in pigs of rye dietary fibre with different structural characteristics. British Journal of Nutrition 80, 457-468.

Gutierrez NA, Serão NVL, Kerr BJ, Zijlstra RT and Patience JF 2014. Relationships among dietary fiber components and the digestibility of energy, dietary fiber and amino acids and energy content of nine corn coproducts fed to growing pigs. Journal of Animal Science 92, 4505-4517.
Hogberg A and Lindberg JE 2004. Influence of cereal non-starch polysaccharides on digestion site and gut environment in growing pigs. Livestock Production Science 87, 121-130.

Holtekjolen AK, Uhlen AK, Brathen E, Sahlstrom S and Knutsen SH 2006. Contents of starch and non-starch polysaccharides in barley varieties of different origin. Food Chemistry 94, 348-358.

Houdijk JGM, Verstegen MWA, Bosch MW and van Laere KJM 2002. Dietary fructooligosaccharides and transgalactooligosaccharides can affect fermentation characteristics in gut contents and portal plasma of growing pigs. Livestock Production Science 73, 175-184.

Imoto S and Namioka S 1978. VFA production in the pig intestine. Journal of Animal Science 47, 467-478.

Izydorczyk MS, Storsley J, Labossiere D, MacGregor AW and Rossnagel BG 2000. Variation in total and soluble beta-glucan content in hulless barley: effects of thermal, physical, and enzymatic treatments. Journal of Agricultural and Food Chemistry 48, 982-989.

Jaworski NW, Lærke HN, Bach Knudsen KE and Stein HH 2015. Carbohydrate composition and in vitro digestibility of dry matter and nonstarch polysaccharides in corn, sorghum, and wheat and coproducts from these grains. Journal of Animal Science 93, 1103-1113.

Jha $R$ and Leterme $P$ 2012. Feed ingredients differing in fermentable fibre and indigestible protein content affect fermentation metabolites and faecal nitrogen excretion in growing pigs. Animal 6, 603-612.

Jha R, Bindelle J, Van Kessel AG and Leterme P 2011a. In vitro fibre fermentation of feed ingredients with varying fermentable carbohydrate and protein levels and protein synthesis by colonic bacteria isolated from pigs. Animal Feed Science and Technology 165, 191-200.

Jha R, Rossnagel B, Pieper R, Van Kessel A and Leterme P 2010. Barley and oat cultivars with diverse carbohydrate composition alter ileal and total tract nutrient digestibility and fermentation metabolites in weaned piglets. Animal 4 724-731

Jha R, Bindelle J, Rossnagel B, Van Kessel AG and Leterme P 2011b. In vitro evaluation of the fermentation characteristics of the carbohydrate fractions of hulless barley and other cereals in the gastrointestinal tract of pigs. Animal Feed Science and Technology 163, 185-193.

Jha R, Overend DN, Simmins PH, Hickling D and Zijlstra RT 2011c. Chemical characteristics, feed processing quality, voluntary feed intake, growth performance, and energy digestibility among wheat classes fed in pelleted diets fed to weaned pigs. Animal Feed Science and Technology 170, 78-90.

Jha R, Owusu-Asiedu A, Simmins PH, Pharazyn A and Zijlstra RT 2012. Degradation and fermentation characteristics of wheat coproducts from flour milling in the pig intestine, studied in vitro. Journal of Animal Science, E-suppl. 90, 173-175. Jha R, Woyengo A, Li J, Bedford MR, Vasanthan T and Zijlstra RT 2015. Enzymes enhance degradation of the fiber-starch-protein matrix of distillers dried grains with solubles as revealed by a porcine in vitro fermentation model and microscopy. Journal of Animal Science 93, 1039-1051.

Jensen BB and Jorgensen $\mathrm{H}$ 1994. Effect of dietary fiber on microbial activity and microbial gas production in various regions of the gastrointestinal tract of pigs. Applied and Environmental Microbiology 60, 1897-1904.

Johansen HN, Bach Knudsen KE, Wood PJ and Fulcher RG 1997. Physicochemical properties and the degradation of oat bran polysaccharides in the gut of pigs. Journal of the Science of Food and Agriculture 73, 81-92.

Jorgensen H, Zaho X and Eggum B 1996. The influence of dietary fibre and environmental temperature on the development of the gastrointestinal tract, digestibility, degree of fermentation in the hind-gut and energy metabolism in pigs. British Journal of Nutrition 75, 365-378.

Jorgensen H, Larsen T, Zhao XQ and Eggum BO 1997. The energy value of shortchain fatty acids infused into the caecum of pigs. British Journal of Nutrition 77, 745-756.

Just A, Fernández J and Jørgensen $H$ 1983. The net energy value of diets for growth in pigs in relation to the fermentative processes in the digestive tract and the site of absorption of the nutrients. Livestock Production Science 10 171-186.

Karr-Lilienthal LK, Kadzere CT, Grieshop CM and Fahey GC Jr 2005. Chemical and nutritional properties of soybean carbohydrates as related to nonruminants: a review. Livestock Production Science 97, 1-12.

Kim JC, Simmins PH, Mullan BP and Pluske JR 2005. The digestible energy value of wheat for pigs, with special reference to the post-weaned animal [Review]. Animal Feed Science and Technology 122, 257-287. 
Konstantinov SR, Awati A, Smidt H, Williams BA, Akkermans ADL and de Vos WM 2004. Specific response of a novel and abundant Lactobacillus amylovorus-like phylotype to dietary prebiotics in the guts of weaning piglets. Applied and Environmental Microbiology 70, 3821-3830.

Lambo AM, Oste R and MEGL Nyman 2005. Dietary fibre in fermented oat and barley beta-glucan rich concentrates. Food Chemistry 89, 283-293.

Le Goff G, van Milgen J and Noblet J 2002. Influence of dietary fibre on digestive utilization and rate of passage in growing pigs, finishing pigs and adult sows. Animal Science 74, 503-515.

Le Goff G, Noblet J and Cherbut C 2003. Intrinsic ability of the faecal microbial flora to ferment dietary fibre at different growth stages of pigs. Livestock Production Science 81, 75-87.

Lee CJ, Horsley RD, Manthey FA and Schwarz PB 1997. Comparisons of betaglucan content of barley and oat. Cereal Chemistry 74, 571-575.

Leterme P, Froidmont $E$, Rossi $F$ and Thewis A 1998. The high water-holding capacity of pea inner fibers affects the ileal flow of endogenous amino acids in pigs. Journal of Agricultural and Food Chemistry 46, 1927-1934.

Leterme $P$, Théwis A, van Leeuwen P, Monmart T and Huisman J 1996. Chemical composition of pea fibre isolates and their effect on the endogenous amino acid flow at the ileum of the pig. Journal of the Science of Food and Agriculture 72, 127-134.

Lindberg JE 2014. Fiber effects in nutrition and gut health in pigs. Journal of Animal Science and Biotechnology 2014, 15-22.

Lizardo R, Peiniau J and Aumaitre A 1997. Inclusion of sugar beet pulp and change of protein source in the diet of the weaned piglet and their effects on digestive performance and enzymatic activities. Animal Feed Science Technology 66, 1-14.

Lunn J and Buttriss JL 2007. Carbohydrates and dietary fibre. Nutrition Bulletin 32, 21-64.

Louis P, Scott KP, Duncan SH and Flint HJ 2007. Understanding the effects of diet on bacterial metabolism in the large intestine. Journal of Applied Microbiology 102, 1197-1208.

Macfarlane GT and Macfarlane S 1993. Factors affecting fermentation reactions in the large bowel. Proceedings of the Nutrition Society 52, 367-373.

Macfarlane GT and Gibson GD 1995. Microbiological aspects of the production of short-chain fatty acids in the large bowel. In Physiological and clinical aspects of short-chain fatty acids (ed. JH Cumming, JL Rombeau and T Sakota), pp. 87-105. Cambridge University Press, Cambridge, UK.

Mariscal-Landin G, Seve B, Colleaux Y and Lebreton Y 1995. Endogenous amino nitrogen collected from pigs with end-to-end ileorectal anastomosis is affected by the method of estimation and altered by dietary fiber. Journal of Nutrition 125, 136-146.

Martensson 0, Biorklund M, Lambo AM, Duenas-Chasco M, Irastorza A, Holst O, Norin E, Welling G, Oste R and Onning G 2005. Fermented, ropy, oat-based products reduce cholesterol levels and stimulate the bifidobacteria flora in humans. Nutrition Research 25, 429-442.

Mateos GG, Martin F, Latorre MA, Vicente B and Lázaro R 2006. Inclusion of oat hulls in diets for young pigs based on cooked maize or cooked rice. Animal Science 82, 57-63.

Molist $F$, van Oostruma M, Pérez JF, Mateos GG, Nyachoti CM and van der Aar PJ 2014. Relevance of functional properties of dietary fibre in diets for weanling pigs. Animal Feed Science and Technology 189, 1-10.

Montagne L, Pluske JR and Hampson DJ 2003. A review of interactions between dietary fibre and the intestinal mucosa, and their consequences on digestive health in young non-ruminant animals. Animal Feed Science and Technology 108, 95-117.

Nielsen TS, Lærke HN, Theil PK, Sørensen JF, Saarinen M, Forssten S and Bach Knudsen KE 2014. Diets high in resistant starch and arabinoxylan modulate digestion processes and SCFA pool size in the large intestine and faecal microbial composition in pigs. British Journal of Nutrition 112, 1837-1849.

Noblet J 2007. Recent developments in net energy research for swine. Advances in Pork Production. In Proceedings of the 2007 Banff Pork Seminar, January 16-19, University of Alberta, Edmonton, AB, Canada, pp. 149-156.

Noblet J and Perez JM 1993. Prediction of digestibility of nutrients and energy values of pig diets from chemical analysis. Journal of Animal Science 71, 3389-3398.

Oakenfull D 2001. Dietary fiber in human nutrition. In Physical chemistry of dietary fiber (ed. GA Spiller), pp. 33-47. CRC Press, Boca Raton, FL, USA.
Owusu-Asiedu A, Patience JF, Laarveld B, Van Kessel AG, Simmins PH and Zijlstra RT 2006. Effects of guar gum and cellulose on digesta passage rate, ileal microbial populations, energy and protein digestibility, and performance of grower pigs. Journal of Animal Science 84, 843-852.

Pedersen C, Boersma MG and Stein HH 2007. Digestibility of energy and phosphorus in 10 samples of distillers dried grains with solubles fed to growing pigs. Journal Animal Science 85, 1168-1176.

Pedersen MB, Dalsgaard S, Bach Knudsen KE, Yu S and Lærke HN 2014. Compositional profile and variation of distillers dried grains with solubles from various origins with focus on non-starch polysaccharides. Animal Feed Science and Technology 197, 130-141.

Pedersen MB, Dalsgaard S, Arenta S, Lorentsena R, Bach Knudsen KE, Yu S and Lærke HN 2015. Xylanase and protease increase solubilization of non-starch polysaccharides and nutrient release of corn- and wheat distillers dried grains with solubles. Biochemical Engineering Journal 98, 99-106.

Pieper R, Jha R, Rossnagel B, Van Kessel AG, Souffrant WB and Leterme P 2008. Effect of barley and oat cultivars with different carbohydrate compositions on the intestinal bacterial communities in weaned piglets. FEMS Microbiology Ecology 66, 556-566.

Pluske JR, Black B, Pethick DW, Mullan BP and Hampson DJ 2003. Effects of different sources and levels of dietary fibre in diets on performance, digesta characteristics and antibiotic treatment of pigs after weaning. Animal Feed Science and Technology 107, 129-142.

Queiroz-Monici KdS, Costa GEA, da Silva N, Reis SMPM and de Oliveira AC 2005. Bifidogenic effect of dietary fiber and resistant starch from leguminous on the intestinal microbiota of rats. Nutrition 21, 602-608.

Roberfroid M 2007. Prebiotics: the concept revisited. The Journal of Nutrition 137, 830-837.

Salunkhe DK, Chavan JK, Adsule RN and Kadam SS 1992. Rapeseeds. In World oilseeds: chemistry, technology, and utilization (ed. DK Salunkhe, JK Chavan, RN Adsule and SS Kadam), pp. 59-96. Van Nostrand Reinhold, New York, NY, USA.

Salvador V, Cherbut C, Barry JL, Bertrand D, Bonnet C and Delort-Laval J 1993. Sugar composition of dietary fibre and short-chain fatty acid production during in vitro fermentation by human bacteria. British Journal of Nutrition 70 , 189-197.

Schiavon S, Bortolozzo A, Bailoni L and Tagliapetra F 2004. Effects of sugar beet pulp on growth and health status of weaned piglets. Italian Journal Animal Science 4, 337-351.

Schmidt-Willig U, Enss M, Coenen M, Gartner K and Hedrich H 1996. Response of rat colonic mucosa to a high fiber diet. Annals of Nutrition and Metabolism 40, 343-350.

Schneeman BO, Diane Richter B and Jacobs LR 1982. Response to dietary wheat bran in the exocrine pancreas and intestine of rats. The Journal of Nutrition 112, 283-286.

Schulze H, van Leeuwen P, Verstegen MWA and Van den Berg JW 1995. Dietary level and source of neutral detergent fiber and ileal endogenous nitrogen flow in pigs. Journal of Animal Science 73, 441-448.

Schulze $H$, van Leeuwen P, Verstegen MW, Huisman J, Souffrant WB and Ahrens F 1994. Effect of level of dietary neutral detergent fiber on ileal apparent digestibility and ileal nitrogen losses in pigs. Journal of Animal Science 72, 2362-2368.

Serena A and Knudsen KEB 2007. Chemical and physicochemical characterisation of co-products from the vegetable food and agro industries. Animal Feed Science and Technology 139, 109-124.

Solá-Oriol D, van Kempen T and Torrallardona D 2010. Relationships between glycaemic index and digesta passage of cereal-based diets in pigs. Livestock Science 134, 41-43.

Taylor JRN and Emmambux MN 2010. Developments in our understanding of sorghum polysaccharides and their health benefits. Cereal Chemical 87, 263-271.

Theander O, Westerlund E, Åman P and Graham H 1989. Plant cell walls and monogastric diets. Animal Feed Science and Technology 23, 205-225.

Thomsen LE, Knudsen KEB, Jensen TK, Christensen AS, Møller K and Roepstorff A 2007. The effect of fermentable carbohydrates on experimental swine dysentery and whip worm infections in pigs. Veterinary Microbiology 119, 152-163. 


\section{Jha and Berrocoso}

Topping DL and Clifton PM 2001. Short-chain fatty acids and human colonic function: roles of resistant starch and non-starch polysaccharides. Physiological Reviews 81, 1031-1064.

Varel VH and Yen JT 1997. Microbial perspective on fiber utilization by swine. Journal of Animal Science 75, 2715-2722.

Varel VH, Pond WG, Pekas JC and Yen JT 1982. Influence of high-fiber diet on bacterial populations in gastrointestinal tracts of obese- and lean-genotype pigs. Applied and Environmental Microbiology 44, 107-112.

Verstegen MWA and Williams BA 2002. Alternatives to the use of antibiotics as growth promoters for monogastric animals. Animal Biotechnology 13 113-127.

Wellock IJ, Houdijk JGM and Kyriazakis I 2007. Effect of dietary non-starch polysaccharide solubility and inclusion level on gut health and the risk of post weaning enteric disorders in newly weaned piglets. Livestock Science 108 186-189.

Widmer MR, McGinnis LM and Stein HH 2007. Energy, phosphorus, and amino acid digestibility of high-protein distillers dried grains and corn germ fed to growing pigs. Journal Animal Science 85, 2994-3003.
Wilfart A, Montagne L, Simmins H, Noblet J and van Milgen J 2007a. Effect of fibre content in the diet on the mean retention time in different segments of the digestive tract in growing pigs. Livestock Science 109, 27-29.

Wilfart A, Montagne L, Simmins PH, van Milgen J and Noblet J 2007b. Sites of nutrient digestion in growing pigs: effect of dietary fiber. Journal Animal Science 85, 976-983.

Williams BA, Verstegen MWA and Tamminga S 2001. Fermentation in the large intestine of single-stomached animals and its relationship to animal health. Nutrition Research Reviews 14, 207-227.

Williams BA, Bosch MW, Awati A, Konstantinov SR, Smidt H, Akkermans ADL, Verstegen MWA and Tamminga S 2005. In vitro assessment of gastrointestinal tract (GIT) fermentation in pigs: Fermentable substrates and microbial activity. Animal Research 54, 191-201.

Wong JMW, de Souza R, Kendall CWC, Emam A and Jenkins DJA 2006. Colonic health: fermentation and short chain fatty acids. Journal of Clinical Gastroenterology 40, 235-243.

Yen JT 2001. Anatomy of the digestive system and nutritional physiology. In Swine nutrition (ed. AJ Lewis and LL Southern), pp. 31-63. CRC Press, Boca Raton, FL, USA. 